\title{
Variabilidade espacial de atributos físicos e químicos relacionados com o estado de agregação de dois Latossolos cultivados no sistema de semeadura direta
}

\author{
Sidney Rosa Vieira ( $\left.{ }^{1 *}\right)$; Sonia Carmela Falci Dechen ('); Glécio Machado Siqueira (1); Guido Dufranc ( $\left.{ }^{2}\right)$ \\ (') Instituto Agronômico (IAC), Centro de Pesquisa e Desenvolvimento de Solos e Recursos Ambientais, Caixa Postal 28, 13020-902, \\ Campinas (SP).E-mail: sidney@iac.sp.gov.br; ( $\left.{ }^{*}\right)$ Autor correspondente; dechen@iac.sp.gov.br; glecio@iac.sp.gov.br \\ (2) Mestre em Agricultura Tropical e Subtropical, Instituto Agronômico - IAC. E-mail: guidodufranc@terra.com.br
}

Recebido: 27/jan./2009; Aceito: 14/jul./2010

\begin{abstract}
Resumo
A variabilidade espacial dos atributos físicos e químicos do solo possui relação direta com a formação e manutenção dos seus agregados. No entanto, os sistemas de manejo do solo também interagem com esses atributos modificando sua variabilidade natural, e consequentemente, a variabilidade do estado de agregação do solo. Assim, este trabalho teve como objetivo estudar a variabilidade espacial de atributos físicos e químicos de dois Latossolos do Estado de São Paulo, sob o sistema de semeadura direta e sua relação com a estabilidade de agregados. As amostras de solo foram coletadas na camada de 0,0 - 0,1 m, utilizando grade de amostragem de 100 m entre pontos. Uma das áreas está localizada no município de Angatuba (SP) e outra no município de Campos Novos Paulista (SP). Os atributos físicos analisados foram: argila, areia grossa, areia fina, areia total e a estabilidade de agregados avaliada por meio do diâmetro médio ponderado dos agregados (DMP). Os atributos químicos estudados foram: matéria orgânica, cálcio e magnésio. Os dados foram analisados por meio da estatística descritiva e de ferramentas geoestatísticas. Uma vez detectada a variabilidade espacial por meio do semivariograma, foram construídos mapas de isolinhas utilizando-se a técnica de interpolação por krigagem. A variabilidade espacial para os atributos físicos e químicos e sua relação com a estabilidade de agregados foi influenciada pelo histórico de manejo das áreas de estudo. Observaram-se valores mais baixos de efeito pepita $\left(C_{0}\right)$, quando comparados aos demais atributos estudados, Latossolo em Campos Novos Paulista. O espaçamento utilizado no Latossolo em Campos Novos Paulista não foi suficiente para detectar a dependência espacial do DMP.
\end{abstract}

Palavras-chave: geoestatística; manejo do solo; física do solo; química do solo; qualidade do solo.

\section{Spatial variability of soil physical and chemical attributes related to agregation status of two Oxisols under no-tillage of the State of São Paulo, Brazil}

\section{Abstract}

The spatial variability of soil physical and chemical attributes presents direct relation with the formation and maintenance of soil aggregates. However, the different soil management systems also interact with these attributes modifying their natural variability. Thus, the objective of this work was to study the spatial variability of the physical and chemical attributes of two Oxisols of the State of São Paulo, under no-tillage system and its relation with the aggregate stability. The soil samples were collected in the $0.0-0.1 \mathrm{~m}$ depth, at the nodes of sampling grid of $100 \mathrm{~m}$ between points. One of the areas is located near Angatuba, SP, Brazil and the other one in Campos Novos Paulista, SP, Brazil. The physical attributes analyzed were: clay content, coarse, fine and total sand contents and the weighed mean aggregate diameter (DMP) as an indicator of aggregate stability. The soil chemical attributes studied were: organic matter, calcium and magnesium contents. The data were analyzed using descriptive statistics and geostatistics tools. Once the spatial dependence has been detected by means of the semivariogram contour maps were constructed using the kriging interpolation technique. The spatial variability for the chemical and physical attributes and their relation to the aggregate stability was influenced by past management history of the areas studied. The Oxisol in Campos Novos Paulista had lower nugget effect $\left(C_{0}\right)$ values. The spacing used in Oxisol in Campos Novos Paulista was not sufficient to detect the spatial dependence of DMP.

Key words: geostatistics; soil tillage systems; soil physical; soil chemical; soil quality. 


\section{INTRODUÇÃO}

Do arranjamento das partículas sólidas do solo resultam sua estrutura e agregação de vital importância para a agricultura, pois estão relacionadas com a disponibilidade de água e de ar para as raízes, com o suprimento de nutrientes, com a resistência mecânica do solo à penetração e com o desenvolvimento radicular.

Griffith et al. (i986) e Neves et al. (2006), descrevem o estado de agregação como um dos parâmetros que podem ser utilizados para medir a qualidade do solo. Um alto índice de agregação indica boa estrutura do solo e influência positiva no crescimento das plantas. Todavia, o estado de agregação do solo está sujeito a alteraçóes devidas a fenômenos naturais e antrópicos, como o uso e manejo. Diferentes atributos do solo influenciam seu estado de agregação, dentre os quais se podem ressaltar: textura (Feller et al., 1996; Dufranc et al., 2004); óxidos de ferro (Fe) e alumínio (Al) (Silva e Kato, 1997; Neves et al., 2006); teor de matéria orgânica (Feller et al., 1996; Silva e Kato, 1997); atividade microbiana (Dufranc et al., 2004) e manejo do solo (Cambardella e Elliot, 1993; Souza et al., 2009).

Para que as partículas minerais primárias formem os agregados, as forças de atração devem exceder as forças de repulsão. A matéria orgânica e as argilas, quando se combinam com os cátions apropriados, são os principais responsáveis pela formação dos agregados, atuando como agentes cimentantes (EMERSON, 1959; BRADY, 1979; Silva e Kato, 1997; Six et al., 2004). Contudo, também é preciso considerar que os cátions trocáveis do solo influem no processo de agregação (ARENA, 1968) de maneira positiva (Série floculante) ou negativa (Série dispersante). Desta maneira, o estado de agregação de um solo é composto por um sistema complexo e intimamente ligado ao manejo, uma vez que nesse processo o solo é manipulado visando à otimização da produtividade.

Série floculante: $\mathrm{Al}>\mathrm{Fe}>\mathrm{H}>\mathrm{Ca}>\mathrm{Mg}>\mathrm{K}>\mathrm{NH}_{4}>\mathrm{Na}>\mathrm{Li}$ : Série dispersante

EDWARDS e Bremner (1967) descrevem que a formação de microagregados origina-se da reação entre moléculas orgânicas, cátions polivalentes $(\mathrm{Fe}, \mathrm{Al}$ e $\mathrm{Ca})$ e partículas de argila; Tisdall e OAdes (1982) descrevem o conceito hierárquico de agregação, em que as partículas primárias livres e agregados de tamanho de silte são unidos por agentes ligantes persistentes, como matéria orgânica humificada ou complexos com cátions polivalentes, óxidos e aluminossilicatos, formando microagregados (20 a $250 \mu \mathrm{m})$; OAdes (1984) acrescentam uma alteração ao modelo hierárquico, na qual propóem que raízes e hifas atuam como núcleos de formação de microagregados e, por serem ligantes temporários, ao se decomporem, formam fragmentos recobertos por mucilagens e incrustados de argilas, dando origem a novos agregados.
Atualmente, tem-se buscado técnicas de produção agropecuária que favoreçam o meio ambiente e a produção sustentável de alimentos. Os sistemas de manejo interagem com os atributos do solo, gerando cenários positivos ou negativos para o desenvolvimento das culturas. O sistema de semeadura direta possui teores de matéria orgânica maiores quando comparados aos do plantio convencional, promovendo, direta ou indiretamente, a maior estabilidade dos agregados. Esses aspectos tornam importante o estudo das modificaçōes que os sistemas de manejo acarretam na agregação do solo e, consequentemente, em sua estrutura. Nesse contexto, o sistema de semeadura direta tem sido amplamente difundido devido às suas vantagens, como diminuição do escorrimento superficial e das perdas por erosão, aumento da quantidade de água infiltrada e pelo aporte de matéria orgânica (MuZILLI, 1981).

VIEIRA (1997) ressalta a importância da incorporação do conhecimento da variabilidade espacial dos atributos do solo ao processo de produçáo agrícola. Nos últimos anos, diversos trabalhos têm demonstrado a importância do conhecimento da variabilidade espacial dos atributos do solo (Souza et al., 1997; Abreu et al., 2003; Grego e VIEIRA, 2005).

Com relação à variabilidade espacial da estabilidade de agregados, Carvalho et al. (2004) descreveram que a distribuição espacial dos agregados não é ao acaso, mas resultante de diferentes processos naturais de formação e manutenção dos agregados e extremamente dependente do sistema de manejo. Assim, este trabalho teve como objetivo estudar a variabilidade espacial de atributos físicos e químicos de dois Latossolos do Estado de Sáo Paulo, sob o sistema de semeadura direta e sua relação com a estabilidade de agregados.

\section{MATERIAL E MÉTODOS}

Uma das áreas localiza-se na Fazenda Planalto, no município de Angatuba (SP), cujas coordenadas geográficas são: $23^{\circ} 29^{\prime} 23^{\prime \prime}$ de latitude Sul e $48^{\circ} 24^{\prime} 46^{\prime \prime}$ de longitude Oeste. Esta área experimental possui 90 ha e é irrigada por meio de um pivô-central cujo raio atinge $500 \mathrm{~m}$. O solo é Latossolo Vermelho Distrófico típico, álico, textura argilosa, A moderado (Embrapa, 1999). O clima da região, segundo a classificação de Köppen, é do tipo Cfa mesotérmico úmido, sem estação seca bem definida, e com regime de chuva de $1.250 \mathrm{~mm}^{-1}$ ano $^{-1}$ (Dufranc, 2001). A área vem sendo manejada com rotaçáo de culturas e semeadura direta desde 1995, envolvendo soja (Glycine max (L.) Merril), milho (Zea mays L.) e batata (Solanum tuberosum L.); esta última cultura introduzida na área a cada três anos e com cultivo convencional.

A outra área está localizada na Fazenda Velha Lagoa, no município de Campos Novos Paulista (SP) cujas 
coordenadas geográficas săo: $22^{\circ} 36^{\prime} 11^{\prime \prime}$ latitude e $50^{\circ} 00^{\prime}$ 09" longitude. A área experimental tem aproximadamente 35 ha, localizada em uma encosta de $400 \mathrm{~m}$ de largura por $880 \mathrm{~m}$ de comprimento. O solo da área é Latossolo Vermelho Distrófico típico, álico, textura média, A moderado (EMBRAPA, 1999). O clima da regiáo, segundo a classificação de Köppen, é do tipo Cfa, tropical úmido sem estação seca, com verôes quentes, geadas pouco frequentes, tendência de concentração das chuvas nos meses de verão e regime de chuva de $1.200 \mathrm{~mm}^{-1} \mathrm{ano}^{-1}$ (Dufranc, 2001). A área vem sendo manejada desde 1995 sob o sistema de semeadura direta com soja (Glycine max (L.) Merril) como cultura de verão e milho (Zea mays L.) como cultura de inverno e, eventualmente, milheto (Pennisetum typhoides Burm. F.) como cultura de primavera.

As amostras foram coletadas em uma grade retangular uniforme, com pontos distanciados de $100 \mathrm{~m}$, no total de 76 pontos de amostragem para a área de Angatuba e 37 pontos para a área de Campos Novos Paulista (Figura 1), após a colheita da cultura de verão, em maio de 2000, na profundidade de $0,0-0,1 \mathrm{~m}$ para análise dos atributos físicos e químicos. Os atributos físicos analisados foram: diâmetro médio ponderado dos agregados (DMP), argila, areia grossa, areia fina e a areia total.

O diâmetro médio ponderado dos agregados (DMP) é obtido por meio da análise da estabilidade de agregados por via úmida, conforme metodologia descrita por CAmargo et al. (1986). O estado de agregaçáo das amostras de solo foi avaliado pelo índice de diâmetro médio ponderado (DMP) e pela percentagem de agregados estáveis em água em cada classe de distribuição. O DMP é obtido de acordo com a Equaçáo 1:

$$
D M P=\sum_{i=1}^{n}\left(X_{i} \times W_{i}\right)
$$

em que: $W_{\mathrm{i}}$ é a proporção de cada classe em relação ao total; $X_{\mathrm{i}}$ é o diâmetro médio das classes de agregados $(\mathrm{mm})$ e $n$ é o número de classes de agregados.

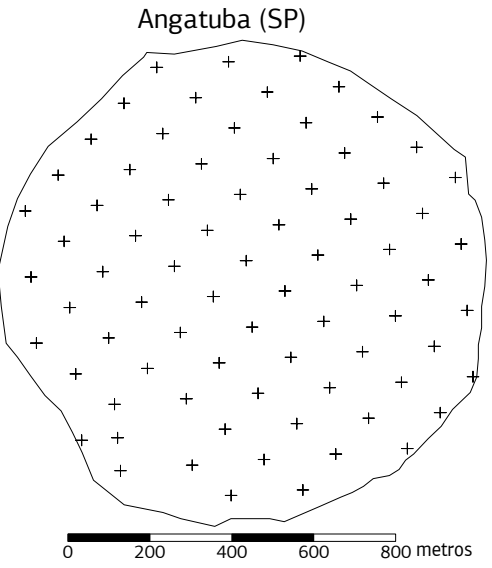

A análise granulométrica do solo foi realizada de acordo com metodologia descrita por CAMARGo et al. (1986). Neste caso, são utilizadas para análise da textura a fração de solo menor que $2 \mathrm{~mm}$ (TFSA), e o dispersante químico uma mistura de hidróxido de $\mathrm{Na}$ e hexametafosfato de $\mathrm{Na}$.

Os atributos químicos analisados relacionados com a estabilidade de agregados foram: matéria orgânica (MO), cálcio $(\mathrm{Ca})$ e magnésio $(\mathrm{Mg})$. A matéria orgânica do solo foi definida por meio de solução de dicromato de sódio em ácido sulfúrico a frio, seguida de determinação colorimétrica do íon crômio proveniente da reação de oxidação, e comparação com leituras de amostras com teores de matéria orgânica determinados pelo método de Walkley-Black. Os resultados de matéria orgânica foram obtidos de uma curva padrão, preparada com as leituras de um conjunto de solos que tiveram a matéria orgânica determinada pelo método de Walkley-Black (RAIJ et al., 2001).

$\mathrm{O} \mathrm{Ca}$ e o $\mathrm{Mg}$ foram determinados por meio da extração de bases com resina trocadora de íons. O princípio do método é a transferência de $\mathrm{Ca}$ e $\mathrm{Mg}$ para a resina trocadora de íons, em meio aquoso. A seguir, foi feita a separação da resina do solo e extração dos elementos da resina com solução ácida de cloreto de sódio (Raij et al., 2001).

Os dados foram analisados por meio do programa Stat (Vieira et al., 2002), que forneceu os principais momentos estatísticos: média, desvio-padrão (DP), coeficiente de variação $(\mathrm{CV})$; valor mínimo (Min.), valor máximo (Máx.), coeficiente de assimetria (Ass.) e coeficiente de curtose (Cur.). Também foram realizadas correlaçôes lineares entre todas as combinações de pares de variáveis, para verificar possíveis relacionamentos entre os atributos analisados. Para determinar a presença de valores extremos (outliers) para o conjunto de dados, foram analisados de acordo com os procedimentos descritos por CAHN et al. (1994).

O conjunto de programas Geoest (VIEIRA et al., 2002) foi utilizado para determinação da dependência

Campos Novos Paulista (SP)

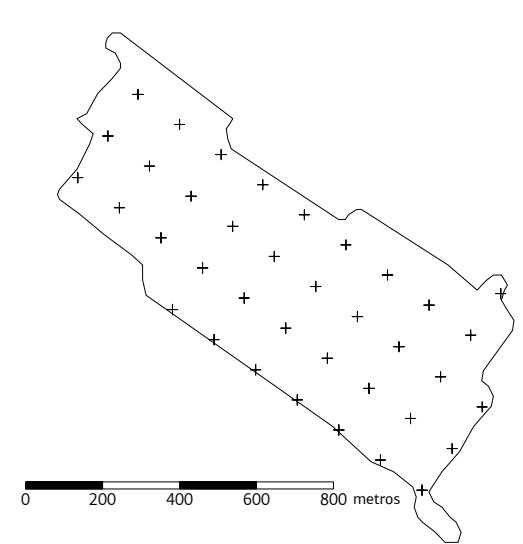

Figura 1. Grade de amostragem em Angatuba (SP) e Campo Novos Paulista (SP) em Latossolo Vermelho distrófico sob o sistema de semeadura direta $(100 \times 100 \mathrm{~m})$. 
espacial entre as amostras por meio do semivariograma experimental (Equação 2):

$\gamma^{*}(h)=\frac{1}{2 N(h)} \sum_{i=1}^{N(h)}\left[Z\left(x_{i}\right)-Z\left(x_{i}+h\right)\right]^{2}$

em que: $\gamma^{*}(h)$ é a semivariancia estimada; $N(h)$ representa o número de pares de valores medidos $Z\left(x_{\mathrm{i}}\right), Z\left(x_{\mathrm{i}}+h\right)$ separados por um vetor (h). Os semivariogramas com dependência espacial foram ajustados ao melhor modelo matemático por meio da validação cruzada, seguindo os procedimentos descritos por VieIRA (2000), possibilitando a determinação dos seguintes parâmetros do semivariograma: $C_{0}$ : efeito pepita; $C_{1}$ : variância estrutural e $a$ : alcance. A razáo de dependência espacial entre amostras foi determinada conforme CAMBARDELla et al. (1994):

$R D=\left(\frac{C_{0}}{C_{0}+C_{1}}\right) 100$

A determinação de valores para os locais não amostrados foi realizada utilizando a técnica interpolação por krigagem (Equação 4), em que os valores não amostrados são estimados utilizando-se os parâmetros de ajuste do semivariograma sem tendência e com variância mínima.

$$
Z^{*}\left(x_{0}\right)=\sum_{i=1}^{N} \lambda_{i} \times Z\left(x_{i}\right)
$$

Em que: $N$ é o número de valores medidos $Z(x$. envolvidos na estimativa; $\lambda_{i}$ são os pesos associados a cada valor medido $Z\left(x_{i}\right)$ e $Z\left(x_{0}\right)$ é o valor estimado (VIeIra, 2000).

Uma vez determinada a dependência espacial entre amostras, foram construídos mapas de isolinhas utilizando-se o programa Surfer 7.0 (Golden Software, 1999).

\section{RESULTADOS E DISCUSSÃO}

Os parâmetros estatísticos dos atributos físicos e químicos do solo em Angatuba (Tabela 1) revelam valores medianos de coeficiente de variação $(\mathrm{CV})$, com exceção dos dados de $\mathrm{Ca}$ e $\mathrm{Mg}$ com C.V. de 28,60\% e 29,86\% respectivamente, cujos valores são considerados altos de acordo com a classificação proposta por GoMEs e GARCIA (2002). Este fato pode estar relacionado com o manejo da área de estudo, uma vez que a cada três anos o solo da área é cultivado com batata (Solanum tuberosum L.) no sistema convencional. De acordo com Souza et al. (1997) e Abreu et al. (2003) o manejo do solo modifica a variabilidade natural dos solos. Nesse contexto, Reis Júnior e Monnerat (2001) descrevem que o manejo praticado na cultura da batata é realizado principalmente com aplicação de elevadas doses de fertilizantes, o que pode ter contribuído para a ocorrência de elevados valores de $\mathrm{CV}$ de $\mathrm{Ca}(\mathrm{CV}=28,60$ $\%)$ e $\mathrm{Mg}(\mathrm{CV}=29,86 \%)$ para o Latossolo em Angatuba. O C.V. para os atributos físicos e químicos do solo em Campos Novos Paulista são baixos, $\mathrm{Mg}, \mathrm{Ca}, \mathrm{MO}$ e a areia grossa possuem valores de C.V. medianos $(21,64 \%$, $18,38 \%, 16,91 \%$ e $12,70 \%$ respectivamente).

Os valores de assimetria e curtose (Tabela 1) indicam que na maioria dos dados não houve distribuição normal, com exceção da areia total em Angatuba. Verifica-se que os valores de assimetria e curtose para $\mathrm{Ca}$ e $\mathrm{Mg}$ em Angatuba também foram influenciados pelo manejo do solo, conforme discutido anteriormente. Os valores mínimo, máximo e média para os atributos físicos indicam que não ocorrem valores extremos (outliers), conforme descrito por CAHN et al. (1994). Contudo, para os atributos químicos as maiores diferenças são notadas para o Latossolo em Angatuba.

Tabela 1. Estatísticas descritivas para os atributos físicos e químicos relacionados com a estabilidade de agregados para o Latossolo em Angatuba (SP) e Campos Novos Paulista (SP)

\begin{tabular}{|c|c|c|c|c|c|c|c|c|c|}
\hline \multirow{2}{*}{ Variável } & Unidade & $\mathbf{N}$ & Média & DP & CV(\%) & Mín. & Máx. & Ass. & Cur. \\
\hline & \multicolumn{9}{|c|}{ Angatuba } \\
\hline MO & $\mathrm{g} \mathrm{dm}^{-3}$ & 75 & 32,32 & 3,87 & 11,97 & 22,00 & 40,00 & $-0,754$ & 0,508 \\
\hline $\mathrm{Ca}$ & $\mathrm{mmol} \mathrm{dm^{-3 }}$ & 75 & 35,65 & 10,19 & 28,60 & 18,00 & 70,00 & 1,168 & 2,291 \\
\hline $\mathrm{Mg}$ & $\mathrm{mmol} \mathrm{dm}^{-3}$ & 75 & 16,68 & 4,981 & 29,86 & 10,00 & 38,00 & 2,048 & 5,526 \\
\hline Argila & $\mathrm{g} \mathrm{kg}^{-1}$ & 75 & 674,30 & 28,79 & 4,27 & 540,10 & 721,00 & $-1,438$ & 5,403 \\
\hline Areia grossa & $\mathrm{g} \mathrm{kg}^{-1}$ & 75 & 53,37 & 8,87 & 16,63 & 33,60 & 72,70 & $-0,134$ & $-0,455$ \\
\hline Areia fina & $\mathrm{g} \mathrm{kg}^{-1}$ & 75 & 125,80 & 21,23 & 16,88 & 81,20 & 225,80 & 1,208 & 5,358 \\
\hline Areia total & $\mathrm{g} \mathrm{kg}^{-1}$ & 75 & 179,20 & 26,36 & 14,71 & 124,40 & 294,90 & 0,943 & 3,870 \\
\hline \multirow[t]{2}{*}{ DMP } & - & 75 & 1,17 & 0,15 & 12,91 & 0,82 & 1,49 & $-0,006$ & $-0,678$ \\
\hline & \multicolumn{9}{|c|}{ Campos Novos Paulista } \\
\hline MO & $g \mathrm{dm}^{-3}$ & 37 & 21,24 & 3,59 & 16,91 & 13,00 & 32,00 & 0,619 & 1,750 \\
\hline $\mathrm{Ca}$ & $\mathrm{mmol} \mathrm{dm}{ }^{-3}$ & 37 & 36,32 & 6,68 & 18,38 & 27,00 & 56,00 & 1,163 & 1,704 \\
\hline $\mathrm{Mg}$ & $\mathrm{mmol} \mathrm{dm}{ }^{-3}$ & 37 & 14,11 & 3,05 & 21,64 & 9,00 & 25,00 & 1,310 & 3,184 \\
\hline Argila & $\mathrm{g} \mathrm{kg}^{-1}$ & 37 & 178,50 & 16,14 & 9,04 & 149,80 & 222,50 & 0,477 & 0,109 \\
\hline Areia grossa & $\mathrm{g} \mathrm{kg}^{-1}$ & 37 & 364,40 & 46,27 & 12,70 & 247,50 & 460,50 & $-0,079$ & 0,455 \\
\hline Areia fina & $\mathrm{g} \mathrm{kg}^{-1}$ & 37 & 407,00 & 33,94 & 8,34 & 342,90 & 477,60 & 0,055 & $-0,546$ \\
\hline Areia total & $\mathrm{g} \mathrm{kg}^{-1}$ & 37 & 771,40 & 20,01 & 2,60 & 725,10 & 817,50 & $-0,235$ & 0,127 \\
\hline DMP & - & 37 & 0,28 & 0,01 & 4,10 & 0,27 & 0,33 & 2,611 & 9,751 \\
\hline
\end{tabular}

N: número de amostras analisadas no final do experimento; DP: desvio-padrăo; CV: coeficiente de variação; Mín: valor mínimo; Máx.: valor máximo; Ass.: assimetria; Cur.: curtose. 
A correlação linear de Pearson entre os atributos para as duas áreas estudadas apenas propiciou bons resultados entre $\mathrm{Ca}$ e $\mathrm{Mg}$ (0,903 em Angatuba e 0,841 em Campos Novos Paulista). Para os parâmetros texturais do solo (argila, areia grossa, areia fina e areia total) também se obteve uma correlação positiva em ambas as áreas, fato já esperado uma vez que o manejo do solo náo influencia a variabilidade destes atributos (GUIMARÁES et al., 2000). As demais correlações lineares proporcionaram baixos valores de coeficiente de correlação principalmente com relação aos dados de DMP e os atributos físicos e químicos para as duas áreas estudadas. Assim, optou-se por não incluir os dados da correlaçáo linear entre todos os atributos neste trabalho, uma vez que não acrescentam nenhuma informação adicional a este estudo.

Os parâmetros de ajuste do semivariograma são apresentados na tabela 2. A grande maioria dos dados ajustouse ao modelo esférico, com exceção do $\mathrm{Mg}$ e da argila em Angatuba que se ajustaram ao modelo exponencial (Figura 2c e 2d) e o DMP em Campos Novos Paulista com efeito pepita puro (Figura 2p). A ocorrência de efeito pepita puro para o DMP em Campos Novos Paulista, indica que o espaçamento utilizado durante o processo de coleta dos dados não foi suficiente para detectar a dependência espacial entre amostras deste atributo. Souza et al. (2009), estudando a variabilidade espacial da estabilidade de agregados na camada de 0,0-0,2 $\mathrm{m}$ de profundidade em um Latossolo Vermelho Distroférico em Guariba (SP), Brasil e de um Latossolo Vermelho Eutroférrico em Jaboticabal (SP), Brasil, cultivados com cana-de-açúcar, ajustou o modelo esférico para o DMP no Latossolo em Guariba e o modelo exponencial para o DMP no Latossolo em Jaboticabal.
A escolha do modelo esférico para a maioria dos atributos coincide com outros trabalhos que descrevem este modelo como o que mais se ajusta aos parâmetros de solo e planta (Salviano et al., 1998; Bertolani e Vieira, 2001). De acordo com Cambardella et al. (1994) e VieiRA (1997), valores elevados de efeito pepita $\left(C_{0}\right)$ correspondem à variabilidade náo detectada durante o processo de amostragem. Desse modo, percebe-se que não há um padrão de ocorrência de valores de $\mathrm{C}_{0} \mathrm{em}$ ambas as áreas de estudo. Todavia, muitos atributos revelam elevados valores de $\mathrm{C}_{0}$ indicando alta descontinuidade da variabilidade espacial, devido à grade de amostragem com espaçamento de $100 \mathrm{~m} \times 100 \mathrm{~m}$. Este fato é confirmado pelos valores de razão de dependência espacial (RD) proposto por Cambardella et al. (1994), onde quanto menor o valor de RD maior a dependência espacial entre as amostras.

O alcance (a) para os atributos físicos e químicos do Latossolo em Angatuba atinge valores de cerca de $500 \mathrm{~m}$, com exceção do $\mathrm{Ca}(200 \mathrm{~m})$ e $\mathrm{Mg}(220 \mathrm{~m})$. Os atributos físicos e químicos do Latossolo em Campos Novos Paulista possuemvalores de alcance (a) em torno dos $350 \mathrm{~m}$. De acordo com Souza et al. (1997), os valores de alcance podem ser utilizados para se definir o espaçamento de coleta de dados. Todavia, deve-se ter em mente que o valor de alcance (a) varia entre os diferentes atributos do solo (Vieira, 2000; Bertolani e Vieira, 2001; Siqueira et al., 2009). Por conseguinte, deve-se considerar também que a variabilidade espacial dos atributos do solo é influenciada pelos diferentes sistema de manejo (Souza et al., 1997; Abreu et al., 2003; Grego e Vieira, 2005), também com distintos padróes de variabilidade ao longo do tempo (Vieira, 2000). Souza et al. (2005) observaram valores de alcance de $19 \mathrm{~m}$ para o DMP em

Tabela 2. Parâmetros de ajuste do semivariograma experimental para os atributos físicos e químicos relacionados com a estabilidade de agregados para o Latossolo em Angatuba (SP) e Campos Novos Paulista (SP)

\begin{tabular}{|c|c|c|c|c|c|c|c|}
\hline \multirow{2}{*}{ Variável } & Modelo & $C_{0}$ & $C_{1}$ & $\mathbf{a}$ & $r^{2}$ & RMSE & RD \\
\hline & \multicolumn{7}{|c|}{ Angatuba } \\
\hline MO & Esférico & 0,00 & 18,71 & 600,00 & 0,884 & 7,00 & 0,00 \\
\hline $\mathrm{Ca}$ & Esférico & 40,00 & 65,00 & 200,00 & 0,933 & 87,02 & 38,09 \\
\hline $\mathrm{Mg}$ & Exponencial & 12,00 & 17,00 & 220,00 & 0,355 & 25,26 & 41,37 \\
\hline Argila & Exponencial & 275,87 & 650,00 & 600,00 & 0,658 & 284,56 & 29,80 \\
\hline Areia grossa & Esférico & 11,65 & 81,89 & 600,00 & 0,841 & 33,73 & 12,46 \\
\hline Areia fina & Esférico & 126,41 & 397,68 & 600,00 & 0,920 & 108,70 & 24,12 \\
\hline Areia total & Esférico & 46,88 & 797,08 & 600,00 & 0,876 & 264,82 & 5,55 \\
\hline \multirow[t]{2}{*}{ DMP } & Esférico & 0,02 & 0,007 & 500,00 & 0,411 & 0,006 & 72,45 \\
\hline & \multicolumn{7}{|c|}{ Campos Novos Paulista } \\
\hline MO & Esférico & 3,68 & 9,91 & 373,37 & 0,3963 & 11,89 & 27,09 \\
\hline $\mathrm{Ca}$ & Esférico & 27,49 & 14,24 & 348,60 & 0,0516 & 58,14 & 65,87 \\
\hline $\mathrm{Mg}$ & Esférico & 4,57 & 4,16 & 392,29 & 0,1583 & 9,79 & 52,33 \\
\hline Argila & Esférico & 168,07 & 100,27 & 500,00 & 0,2212 & 221,04 & 62,63 \\
\hline Areia grossa & Esférico & 31,90 & 3029,03 & 500,00 & 0,6792 & 2731,25 & 1,04 \\
\hline Areia fina & Esférico & 0,00 & 1504,28 & 415,45 & 0,7264 & 1157,18 & 0,00 \\
\hline Areia total & Esférico & 243,98 & 220,32 & 500,00 & 0,3434 & 365,06 & 52,55 \\
\hline DMP & \multicolumn{7}{|c|}{ Efeito pepita puro } \\
\hline
\end{tabular}

$\mathrm{C}_{0}$ : efeito pepita; $\mathrm{C}_{1}$ : variância estrutural; a: alcance; $\mathrm{r}^{2}$ : coeficiente de correlaçẫo; RMSE: desvio quadrático médio relativo; RD: razăo de dependência espacial entre amostras. 
Latossolo Vermelho Distroférrico, em Guariba, e de 34 $\mathrm{m}$ para Latossolo Vermelho eutroférrico, em Jaboticabal, com valores de efeito pepita $\left(\mathrm{C}_{0}=0,001\right.$ e 0,46 respectivamente) similares ao constatado neste estudo para o Latossolo em Angatuba $\left(\mathrm{C}_{0}=0,02\right)$.

Por outra parte, verifica-se que em ambas as áreas em estudo foram observados elevados valores de $\mathrm{C}_{0} \mathrm{e}$ muitos dos atributos possuem RD com média e baixa dependência espacial entre amostras. Neste caso, um aumento do espaçamento entre amostras poderia diminuir o tempo e o custo gasto com a coleta e a análise dos dados, mas não assegura que a variabilidade espacial possa ser modelada por meio do semivariograma com a acurácia necessária para a prática da agricultura de precisão. É importante lembrar que, para a área em Campos Novos Paulista o espaçamento regular de $100 \mathrm{~m}$ náo foi suficiente para detectar a dependência espacial entre amostras para o DMP.

O coeficiente de correlação de ajuste do semivariograma $\left(\mathrm{r}^{2}\right)$ revela que os melhores ajustes foram realizados para o Latossolo em Angatuba. Todavia, é preciso considerar que os atributos do Latossolo em Campos
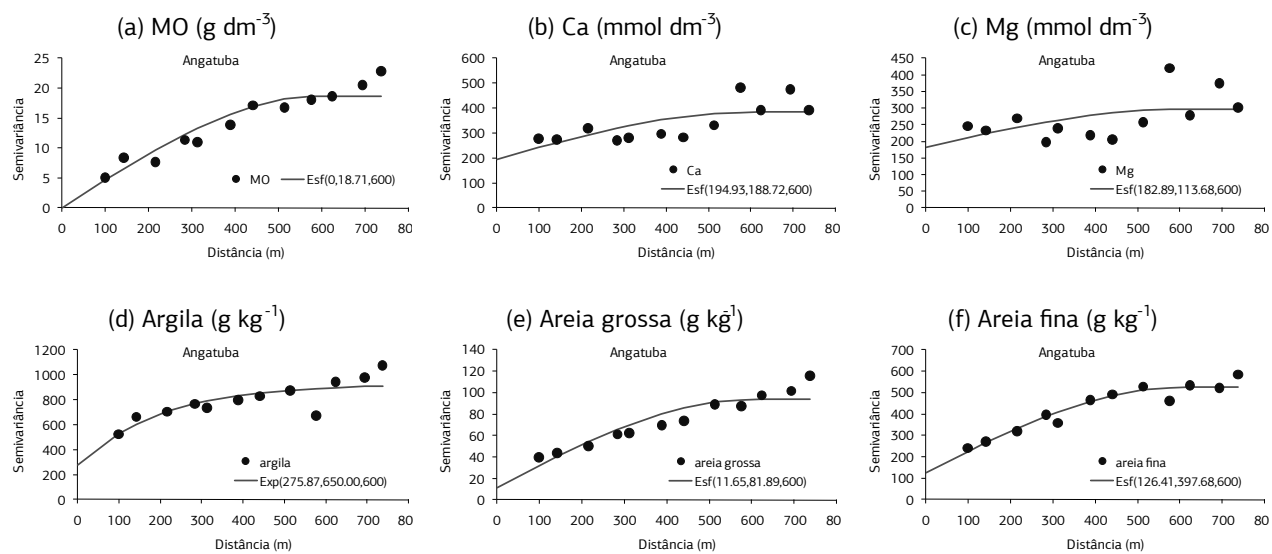

(e) Areia grossa $\left(\mathrm{g} \mathrm{kg}^{-1}\right)$
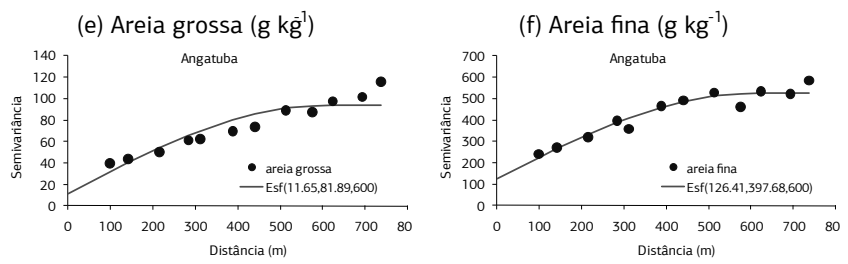

(g) Areia Total $\left(\mathrm{g} \mathrm{kg}^{-1}\right)$
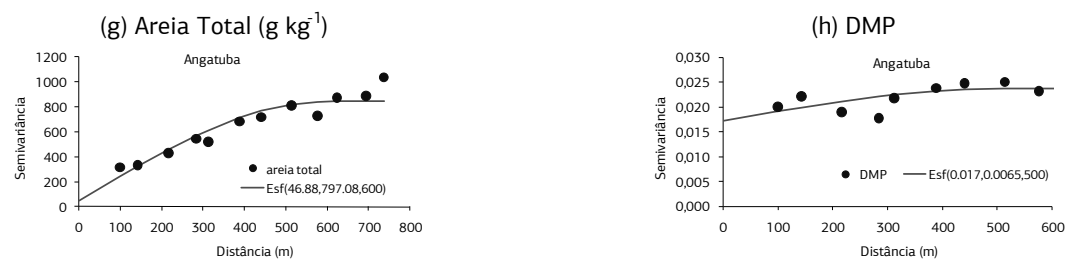

(i) $\mathrm{MO}\left(\mathrm{g} \mathrm{dm}^{-3}\right)$

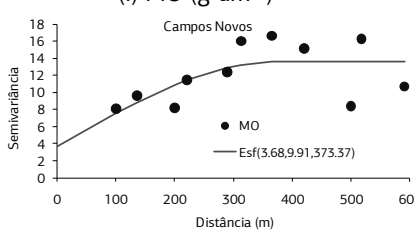

(I) Argila $\left(\mathrm{g} \mathrm{kg}^{-1}\right)$

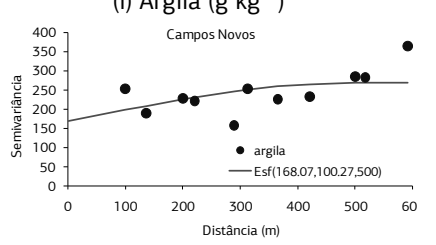

(o) Areia Total $\left(\mathrm{g} \mathrm{kg}^{-1}\right)$

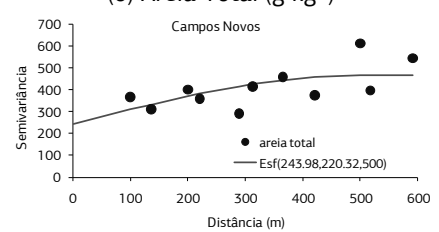

(j) Ca (mmol dm $\left.\mathrm{m}^{-3}\right)$

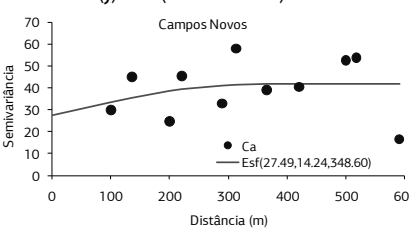

(m) Areia grossa $\left(\mathrm{g} \mathrm{kg}^{-1}\right.$ )

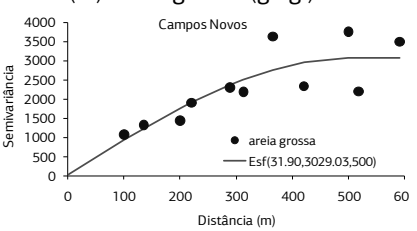

(k) $\mathrm{Mg}\left(\mathrm{mmol} \mathrm{dm}^{-3}\right)$

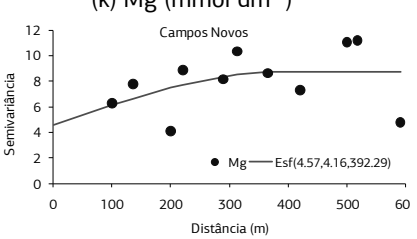

(n) Areia fina $\left(\mathrm{g} \mathrm{kg}^{-1}\right)$

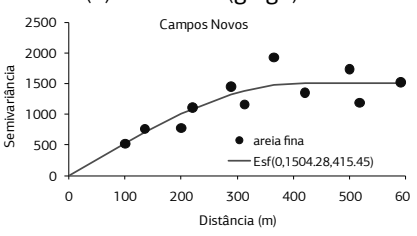

(p) DMP

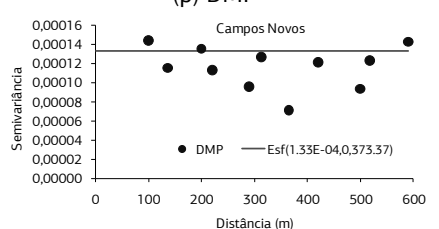

Figura 2. Semivariograma experimental para os atributos físicos e químicos estudados para o Latossolo em Angatuba, SP (a-h) e Campos Novos Paulista, SP (i-p). 
Novos Paulista tiveram os menores valores de $\mathrm{C}_{0}$ indicando uma maior representatividade da variabilidade espacial destes atributos para a área de estudo, com exceção da areia total que indica valor de $\mathrm{C}_{0}$ de 243,08 . O fato de ocorrer maior erro amostral descrito pelos valores de $\mathrm{C}_{0}$ nos atributos do Latossolo, em Angatuba pode ser reflexo do manejo do solo interferindo sobre a variabilidade espacial das propriedades em estudo (Souza et al., 1997; Abreu et al., 2003; Grego e Vieira, 2005). Neste caso, também deve-se considerar que os elevados valores de efeito pepita $\left(\mathrm{C}_{0}\right)$ são decorrentes do espaçamento utilizado ( $100 \mathrm{~m} \times 100 \mathrm{~m}$ ), uma vez que, se o espaçamento fosse menor seria possível detectar padróes de variabilidade que não foram detectados, diminuindo os valores de efeito pepita $\left(\mathrm{C}_{0}\right)$.

Pela análise da figura 2, constata-se que em ambas as áreas não ocorre um padrão de distribuição espacial dos pares de semivariância entre os atributos em estudos. As maiores diferenças entre as estruturas espaciais (Figura 2) são decorrentes principalmente pela ação do manejo sobre os atributos do solo (Souza et al., 1997; Abreu et al., 2003). Por outro lado, também é preciso considerar a posição das áreas de estudo na paisagem. Marques JúNIOR (1995) descreve que a variabilidade dos atributos do solo é influenciada pela sua localização na paisagem ou no declive, mesmo que esse seja de pequena expressão. Assim, a análise conjunta dos parâmetros de ajuste do semivariograma e da posição de cada uma das áreas em estudo na paisagem pode ser útil para melhor compreensão do padrão espacial dos mapas de isolinhas (Figuras $3 \mathrm{e}$ 4) para os diferentes atributos analisados.

Os mapas de isolinhas para o Latossolo em Angatuba (Figura 3) confirmam haver uma relação entre os diferentes atributos físicos e químicos relacionados com a estabilidade de agregados. Percebe-se que, nas áreas com maior conteúdo de $\mathrm{MO}$ (Figura 3a) há maior DMP (Figura $3 \mathrm{~h}$ ), uma vez que, a interação entre as partículas básicas do solo (argila, silte e areia) e os agentes cimentantes (MO e óxidos de Fe e $\mathrm{Al}$ ), determina seu estado de agregação (Brady, 1979; Silva e Kato, 1997). SouZa et al.(2009), estudando a variabilidade espacial da estabilidade de agregados em Latossolos cultivados com canade-açúcar verificou maior estabilidade de agregados nas áreas com maior conteúdo de matéria orgânica. Os efeitos da matéria orgânica na agregação são relatados na literatura por vários autores (SÁ et al., 2000; CORRÊA, 2002). WoHlenberg et al. (2004) e ANDrade et al. (2009) não observaramcorrelação significativa entre o DMP e o conteúdo de matéria orgânica, justificando que, apesar da variação de carbono orgânico, outros fatores corroboram para a melhoria do DMP, como: interação matéria orgânica, conteúdo de argila e cátions do solo $(\mathrm{Fe}, \mathrm{Al}$ e Ca) favorecendo o estado de agregação (EDwards e Bremner, 1967; Brady, 1979 e Silva e Kato, 1997); ação da matéria orgânica humificada ou complexos com cátions polivalentes, óxidos e aluminossilicatos, formando microagregados (Tisdall e OAdes, 1982) e atuação de raízes e hifas para a formação de microagregados (OAdes, 1984; Dufranc et al., 2004).

Também se verifica que existe uma relação entre os atributos para as duas áreas com maior teor de argila e menor teor de areia para a formação dos agregados. Este fato pode ser explicado, uma vez que os óxidos de $\mathrm{Fe}$ (hematita e goethita) e $\mathrm{Al}$ (gibsita) estáo presentes nas argilas (Silva e Kato, 1997), daí os maiores valores de DMP nas zonas com maior conteúdo de argila. DufranC et al. (2004), estudando a influência dos diferentes agentes agregantes para a mesma área em estudo concluiu que a MO é o principal agente agregante para esta área de estudo.

Com relação à interação dos mapas de $\mathrm{Ca}$ e $\mathrm{Mg}$ com o DMP (Figuras 3b, c e h), percebe-se que nas áreas com maior concentração de $\mathrm{Ca}$ e $\mathrm{Mg}$ houve um decréscimo nos valores de MO e DMP (Figuras 3a e h). Westerhof et al. (1999) e Albuquerque et al. (2003) descrevem que a perda de matéria orgânica e as alteraçóes químicas advindas do uso de corretivos e adubos podem alterar as características físicas do solo. Nesse contextyo, o Ca e o $\mathrm{Mg}$ em primeiro momento e em quantidades adequadas funcionam como agentes agregantes (BRADY, 1979). Todavia, o excesso desses elementos no solo favorece a dispersão das argilas (ARENA, 1968), favorecendo a diminuiçâo da estabilidade de agregados. Assim, o manejo do solo com cultivo de batata (Solanum tuberosum L.) a cada três anos no sistema convencional pode estar contribuindo para a perda da matéria orgânica (Westerhof et al., 1999) e concentração de corretivos e fertilizantes em algumas zonas (Albuquerque et al., 2003) no Latossolo em Angatuba. No entanto, mesmo se este fato estiver ocorrendo, os mapas de variabilidade espacial dos atributos estudados em Angatuba, verifica-se um padrão similar de distribuição das linhas de contorno.

Também é preciso considerar que nas zonas com menor conteúdo de $\mathrm{MO}$ e maior conteúdo de $\mathrm{Ca}$ e $\mathrm{Mg}$ também há acréscimo dos teores de areia, principalmente areia fina (Figura 3f). De acordo com Feller et al. (1996) e Dufranc et al. (2004), áreas com maior conteúdo de areia fina possuem menores valores de estabilidade de agregados. Com isso, na parte inferior da área do Latossolo em Angatuba ocorre uma associação entre os diferentes atributos estudados que favorece a menor estabilidade de agregados nessa zona da área.

Para o Latossolo, em Campos Novos Paulista (Figura 4), é difícil relacionar os atributos físicos e químicos com o DMP, uma vez que ocorreu efeito pepita puro, impossibilitando a construção do seu respectivo mapa de isolinhas. Contudo, pode-se fazer um estudo comparando os mapas dos atributos físicos e químicos envolvidos neste estudo. A área de estudo está sendo manejada com semeadura direta desde 1995, com rotação de culturas. Percebe-se 
que, não há relação entre o mapa de variabilidade espacial de $\mathrm{MO}$ e de argila, pois as zonas com maior $\mathrm{MO}$ não são necessariamente as zonas com maior conteúdo de argila. $\mathrm{O}$ mesmo fato ocorre com o $\mathrm{Ca}$ e o $\mathrm{Mg}$.

Nos demais atributos estudados em Campos Novos Paulista também não há nenhuma relação clara entre os mapas de isolinhas. Embora, não seja possível construir o mapa de isolinhas do DMP, espera-se que seu comportamento espacial para a área de estudo seja similar ao

(a) Matéria orgânica (MO, $\left.\mathrm{g} \mathrm{dm}^{-3}\right)$

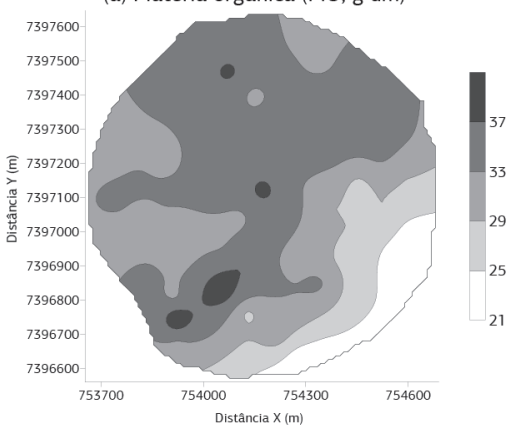

(c) Magnésio ( $\left.\mathrm{Mg}, \mathrm{mmol} \mathrm{dm}^{-3}\right)$
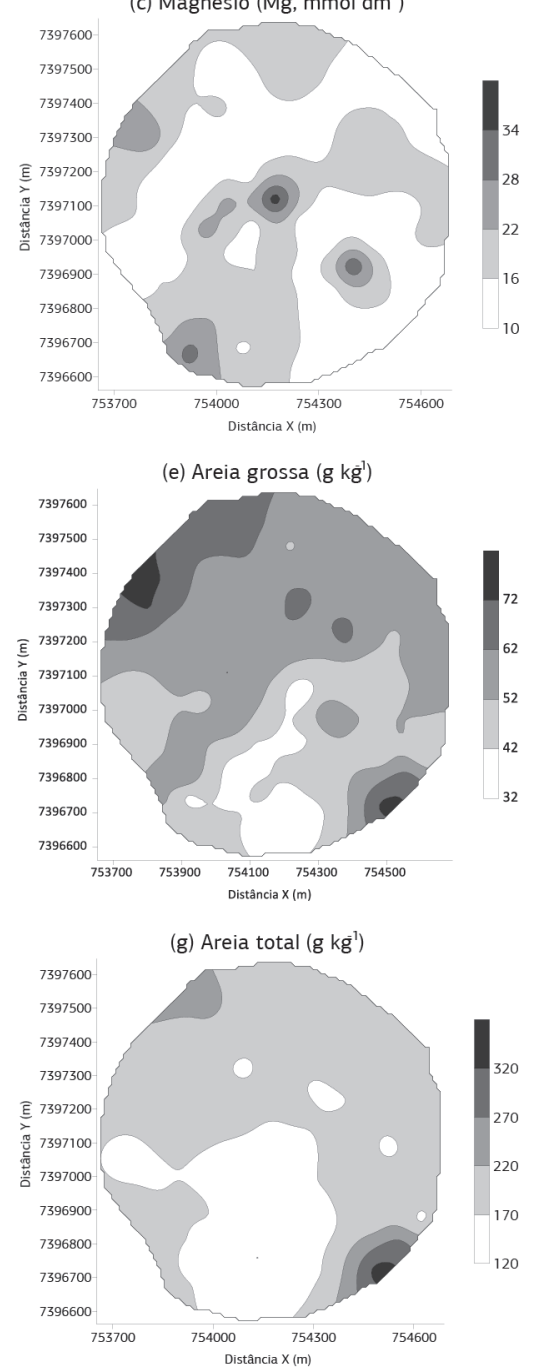

comportamento espacial da $\mathrm{MO}$ e da argila (Figura 4a e d), uma vez que estes dois elementos são os principais responsáveis pelo estado de agregaçáo do solo (BRADY, 1979; SiLVA e Kato, 1997). Todavia, Dufranc et al. (2004), estudando a importância dos diferentes agentes agregantes para esta mesma área de estudo por meio de correlaçôes lineares múltiplas, demonstraram que para esta mesma área os agentes cimentantes mais importantes foram a comunidade bacteriana e os teores de Fe e de K. A variabilidade espacial
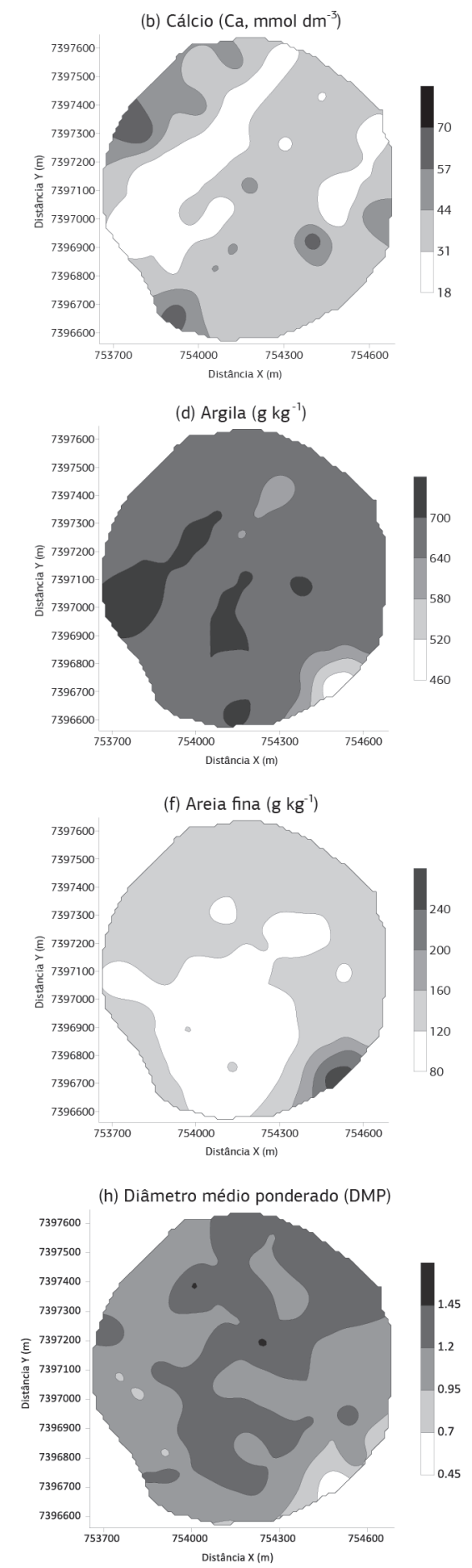

Figura 3. Mapas de variabilidade espacial para os atributos físicos e químicos relacionados com a estabilidade de agregados em Angatuba (SP). 
dos parâmetros citados pelo autor anteriormente, não fazem parte deste estudo, então é difícil fazer uma predição do comportamento espacial do DMP para esta área de estudo, mesmo porque o espaçamento utilizado não foi suficiente para detectar sua variabilidade espacial.

Pode-se ainda considerar, que as zonas com elevado teor de areia fina tendem a proporcionar baixa estabilidade de agregados (Dufranc et al., 2004). Esta afirmação é importante, pois contribui para a inter-relação dos parâmetros texturais do solo, com o teor de matéria orgânica e a estabilidade de agregados. Nesse contexto, é de se esperar que os maiores valores de estabilidade de agregados para o Latossolo em Campos Novos Paulista estejam presentes na metade superior da área de estudo, zona que concentra aparentemente os maiores teores de argila e de matéria orgânica.
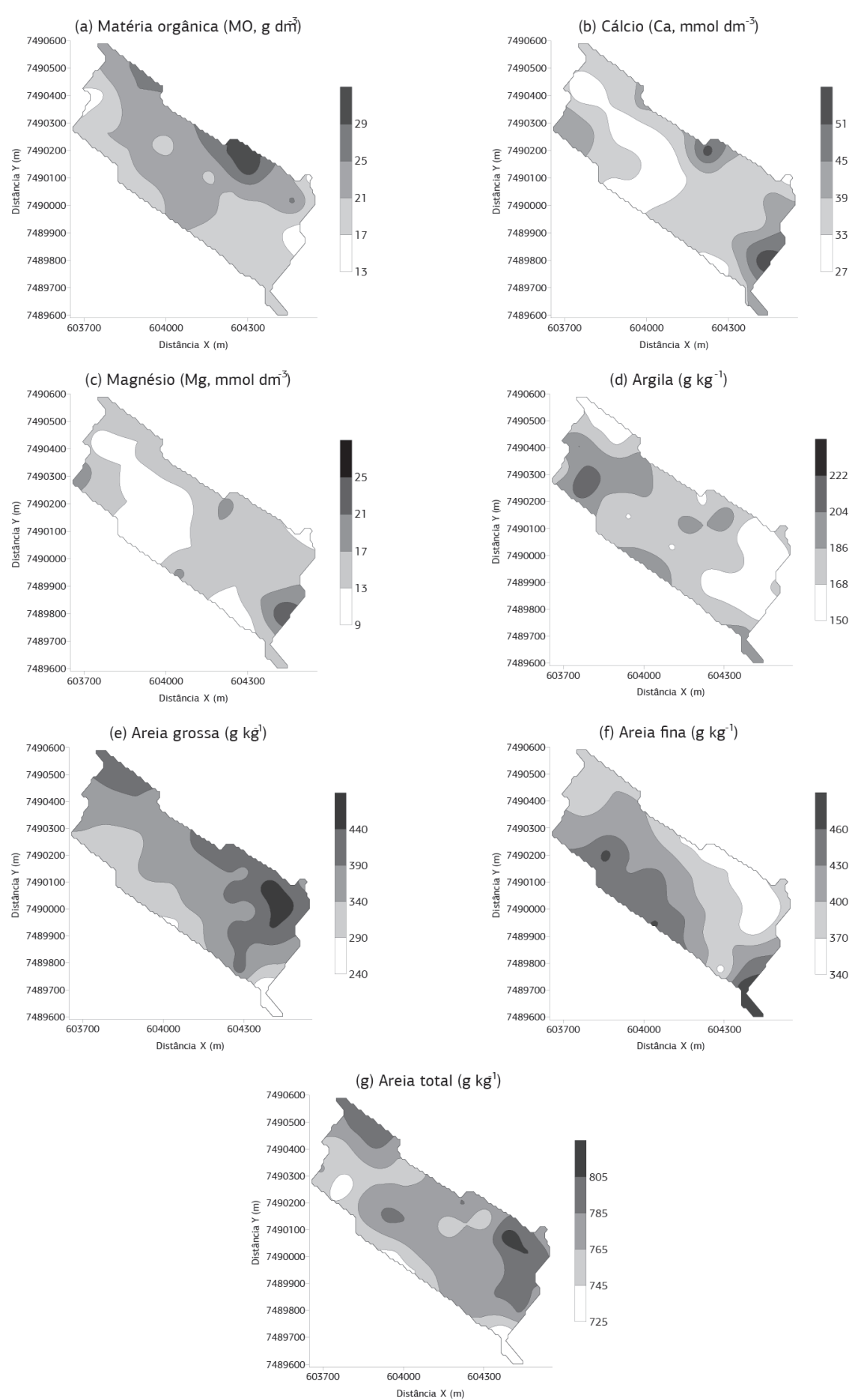

Figura 4. Mapas de variabilidade espacial para os atributos físicos e químicos relacionados com a estabilidade de agregados em Campos Novos Paulista (SP). 


\section{CONCLUSÕES}

1. A variabilidade espacial para os atributos físicos e químicos e sua relação com a estabilidade de agregados é influenciada pelo histórico de manejo das áreas de estudo.

2. Observa-se no Latossolo em Campos Novos Paulista os valores mais baixos de efeito pepita $\left(\mathrm{C}_{0}\right)$, todavia, o ajuste do semivariograma para esta área náo propicia bons valores de coeficientes de correlação $\left(r^{2}\right)$.

3. O espaçamento utilizado no Latossolo em Campos Novos Paulista não é suficiente para detectar a dependência espacial do DMP, dificultando descrever sua relação com os demais atributos físicos e químicos envolvidos neste estudo.

\section{AGRADECIMENTOS}

Ao PRODETAB - Banco Mundial pelo financiamento deste projeto. Aos parceiros do Instituto Agronômico, a Antônio Carlos Rodrigues e José Antonio Furtado, proprietários da Fazenda Planalto em Angatuba (SP), e aos irmãos José Roberto e Lúcio Borges, proprietários da Fazenda Velha Lagoa, em Campos Novos Paulista (SP). Ao Ministério de Assuntos Exteriores e de Cooperação do Governo da Espanha (MAEC-AECID), pela concessão de bolsa de doutorado para o terceiro autor.

\section{REFERÊNCIAS}

ABREU, S.L.; REICHERT, J.M.; SILVA, V.R.; REINERT, D.J.; BLUME, E. Variabilidade espacial de propriedades físico-hídricas do solo, da produtividade e da qualidade de grãos de trigo em Argissolo Franco Arenosos sob plantio direto. Ciência Rural, v.33, p.275-282, 2003.

ALBUQUERQUE, J.A.; BAYER, C.; ERNANI, P.R.; MAFRA, A.L.; FONTANA, E.C. Aplicação de calcário e fósforo e estabilidade da estrutura de um solo ácido. Revista Brasileira de Ciência do Solo, v.27, p.799-806, 2003

ANDRADE, R.S.; STONE, L.F.; SILVEIRA, P.M. Culturas de cobertura e qualidade física de um Latossolo em plantio direto. Revista Brasileira de Engenharia Agrícola e Ambiental, v.13, p.411418, 2009.

ARENA, A. Curso de Suelos - Física de Suelos. Rio de janeiro: Centro Pan-Americano de Aperfeiçoamento para Pesquisas de Recursos Naturais (CEPERN), Instituto Pan-Americano de Geografia e História, OEA e Ministério da Agricultura do Brasil. 1968. 72p.

BERTOLANI, F.C.; VIEIRA, S.R. Variabilidade espacial da taxa de infiltração de água e da espessura do horizonte A, em um Argissolo Vermelho-Amarelo, sob diferentes usos. Revista Brasileira de Ciência do Solo, v.25, p.987-995, 2001.
BRADY, N.C. Natureza e propriedades dos solos. 5.ed. Rio de Janeiro: Freitas Bastos, 1979. p.60-64.

CAHN, M.D.; HUMMEL, J.W.; BROUER, B.H. Spatial analysis of fertility for sitespecific crop management. Soil Science Society of America Journal, v.58, p.1240-1248, 1994.

CAMARGO, O.A.; MONIZ, A.C; JORGE, J.A.; VALADARES, J.M.A.S. Métodos de análise química, mineralógica e física de solos do Instituto Agronômico de Campinas. Campinas: Instituto Agronômico, 1986, 94p. (Boletim técnico, 106)

CAMBARDELLA, C.A.; ELLIOT, E.T. Carbon and nitrogen distribution in aggregates from cultivated and native grassland soils. Soil Science Society of America Journal, v.57, p.1071-1076, 1993.

CAMBARDELLA, C.A.; MOORMAN, T.B.; NOVAK, J.M.; PARKIN, T.B.; KARLEN, D.L.; TURCO, R.F.; KONOPKA, A.E. Field-scale variability of soil properties in Central Iowa Soil. Soil Science Society of America Journal, v.58, p.1501-1511, 1994.

CARVALHO, J.R.P.; DECHEN, S.C.F.; DUFRANC, G. Variabilidade espacial da agregação do solo avaliada pela geometria fractal e geoestatística. Revista Brasileira de Ciência do Solo, v.28, p.1-9, 2004.

CORRÊA, J.C. Efeito de sistemas de cultivo na estabilidade de agregados de um Latossolo Vermelho-Amarelo em Querência, MT. Pesquisa Agropecuária Brasileira, v.37, p.203-209, 2002.

DUFRANC, G. Atributos físicos, químicos e biológicos relacionados com a estabilidade de agregados de dois Latossolos Vermelhos em plantio direto no estado de Sáo Paulo. 2001. 143p. Dissertação (Mestrado em Agricultura Tropical e Subtropical) Instituto Agronômico-IAC, Campinas.

DUFRANC, G.; DECHEN, S.C.F.; FREITAS, S.S.; CAMARGO, O.A. Atributos físicos, químicos e biológicos relacionados com a estabilidade de agregados de dois Latossolos em plantio direto no Estado de São Paulo. Revista Brasileira de Ciência do Solo, v.28, p. 505-517, 2004.

EDWARDS, A.P.; BREMNER, J.M. Dispersion of soil particles by sonic vibration. European Journal of Soil Science, v.18, p.47-63, 1967.

EMBRAPA. Centro Nacional de Pesquisa de Solos. Sistema brasileiro de classificaçáo de solos. Brasília: Embrapa, Produção de Informação; Rio de Janeiro: Embrapa Solos, 1999. 412p.

EMERSON, W.W. The structure of soil crumbs. European Journal Soil Science, v.10, p.235-244, 1959.

FELLER, C.; ALBRECHT, A.; TESSIER, D. Aggregation and organic matter storage in kaolinitic and smectitic tropical soils. In: CARTER, M.R.; STEWART, B.A. (Ed.). Structure and organic matter storage in agricultural soils. Boca Raton: Lewis, 1996. p.309-359.

GOLDEN SOFTWARE. Surfer: User's Guide (Versión 7.0). Golden, CO, EEUU, 1999. 679p.

GOMES, F.P., GARCIA, C.H. Estatística aplicada a experimentos agronômicos e florestais. Piracicaba: FEALQ, 2002. 309p. 
GREGO, C.R.; VIEIRA, S.R. Variabilidade espacial de propriedades físicas do solo em uma parcela experimental. Revista Brasileira de Ciência do Solo, v.29, p.169-177, 2005.

GRIFFITH, D.R.; MANNERING, J.V.; BOX, J.E. Soil and moisture management with reduced tillage. In: SPRAGUE, M.A.; TRIPLLET, G.B. (Ed.). No-tillage and surface-tillage agriculture - the tillage revolution. New York: John Wiley, 1986. p.19-57.

GUIMARÁES, E.C. Variabilidade espacial de atributos de uma Latossolo Vermelho-escuro, textura argilosa, da região do cerrado, submetido ao plantio direto e ao plantio convencional. 2000. $85 \mathrm{f}$. Tese (Doutorado) UNICAMP, Campinas.

MARQUES JÚNIOR, J. Distribuição e atributos dos solos em relaçáo à forma e evoluçáo de uma vertente em Monte Alto, SP. 1995. 226f. Tese (Doutorado em Agronomia) - Escola Superior em Agricultura Luiz de Queiroz, Universidade de São Paulo, Piracicaba.

MUZILLI, O.O. Manejo da Fertilidade do Solo, In; IAPAR, Plantio Direto no Estado do Paraná. Londrina: IAPAR, 1981. p.43-58. (Circular n. ${ }^{\circ}$ 23)

NEVES, C.S.V.J.; FELLER, C.; KOUAKOUA, C.F. Efeito do manejo do solo e da matéria orgânica solúvel em água quente na estabilidade de agregados de um latossolo argiloso. Ciência Rural, v.36, p.1410-1415, 2006.

OADES, J.M. Soil organic-matter and structural stability mechanisms and implications for management. Plant and Soil, v.76, p.319-337, 1984.

RAIJ, B. van; ANDRADE, J.C.; CANTARELLA H.; QUAGGIO, J.A. Análise química para avaliação da fertilidade de solo tropicais. Campinas: Instituto Agronômico, 2001, 285 p.

REIS JÚNIOR, R. A.; MONNERAT, P. H. Exportação de nutrientes nos tubérculos de batata em função de doses de sulfato de potássio. Revista Horticultura Brasileira, v.19, p.360-364. 2001.

SÁ, M.A.C.; LIMA, J.M.; SILVA, M.L.N.; DIAS JUNIOR, M.S. Comparaçáo entre métodos para estudo da estabilidade de agregados em Solo. Pesquisa Agropecuária Brasileira, v.35, p.2043-2053, 2000.

SALVIANO, A.A.C.; VIEIRA, S.R.; SPAROVEK, G. Variabilidade espacial de atributos de solo e de crotalaria juncea L. em área severamente erodida. Revista Brasileira de Ciência do Solo, v.22, p.115-122, 1998.

SILVA, C.L.; KATO, E. Efeito do selamento superficial na condutividade hidráulica saturada da superfície de um solo sob cerrado. Pesquisa Agropecuária Brasileira, v.32, p.213-220, 1997.
SIQUEIRA, G.M.; VIEIRA, S.R.; DECHEN, S.C.F. Variabilidade espacial da densidade e da porosidade de um Latossolo Vermelho Eutroférrico sob semeadura direta por vinte anos. Bragantia, v.68, p.751-759, 2009.

SIX, J.; BOSSUYT, H.; DEGRYZE, S.; DENEF, K. A history of research on the link between (micro) agregates, soil biota, and soil organic matter dynamics. Soil and Tillage Research, v.79, p.7-31, 2004.

SOUZA, L.S.; COGO, N.P.; VIEIRA, S.R. Variabilidade de propriedades físicas e químicas do solo em um pomar cítrico. Revista Brasileira de Ciência do Solo, v.21, p.367-372, 1997.

SOUZA, Z.M.; MARQUES JUNIOR, J.; PEREIRA, G.T.; SÁEZ, C.M.S. Spatial variability of aggregate stability in Latosols under sugarcane. Revista Brasileira de Ciência do Solo, v.33, p.245-253, 2009.

SURFER for windows. Realese 7.0. Contouring and 3D surface mapping for scientist's engineers. User's guide. New York: Golden Software, 1999. 619p.

TISDALL, J.M.; OADES, J.M. Organic matter and water-stable aggregates in soil. Journal of Soil Science Society, v.33, p.141-163, 1982.

VIEIRA, S.R. Geoestatística em estudos de variabilidade espacial do solo. In: NOVAIS, R.F., ALVAREZ, V.H., SCHAEFER, G.R. (Ed.). Tópicos em Ciência do solo. Viçosa: Sociedade Brasileira de Ciência do Solo, v.1, 2000. p. 1-54.

VIEIRA, S.R. Variabilidade espacial de argila, silte e atributos químicos em uma parcela experimental de um Latossolo Roxo de Campinas (SP). Bragantia, v.56, p.181-190,1997.

VIEIRA, S.R.; MILLETE, J.; TOPP, G.C.; REYNOLDS, W.R. Handbook for geostatistical analysis of variability in soil and climate data. In: ALVARES, V.H.; SCHAEFER, C.E.G.R.; BARROS, N.F.; MELLO, J.W.V.; COSTA, L.M. Tópicos em Ciência do Solo. Viçosa: UFV, 2002. v.2, p.1-46.

WESTERHOF, R.; BUURMAN, P.; van GRIETHUYSEN, C.; AYARZA, M.; VILELA, L.; ZECH, W. Aggregation studied by laser diffraction in relation to plowing and liming in the Cerrado region in Brazil. Geoderma, v.90, p.277-290, 1999.

WOHLENBERG, E.V.; REICHERT, J.M.; REINERT, D.J.; BLUME, E. Dinâmica da agregaçáo de um solo franco-arenoso em cinco sistemas de culturas em rotação e em sucessão. Revista Brasileira de Ciência do Solo, v.28, p.891-900, 2004. 